\title{
MEASUREMENT OF THE TUNNELING AND HOPPING PARAMETERS IN Ru0 2 THICK FILMS
}

\author{
N.C. HALDER and R.J. SNYDER \\ Department of Physics, University of South Florida Tampa, Florida 33620
}

(Received July 14, 1982; in final form March 10, 1983)

\begin{abstract}
Thick film resistors containing a mixture of ruthenium oxide $\left(\mathrm{RuO}_{2}\right)$ and lead borosilicate $\left(\mathrm{Pb}_{5} \mathrm{~B}_{2} \mathrm{SiO}_{10}\right)$ have been produced on alumina $\left[\left(\mathrm{Al}_{2} \mathrm{O}_{3}\right)_{.96}(\mathrm{MgO})_{.04}\right]$ substrates. The temperature coefficient of resistivity (TCR) of these films has been measured for different particle size and concentration (weight percentage) of the conductor particles. The TCR was found to be a function of temperature in all the films included here. From the measured values of negative TCR the tunneling parameter $\alpha$ and hopping parameter $\beta$ were determimed. These results suggest that hopping is important for the low concentration films. For films with positive TCR only parameter $\alpha$ could be determined. The parameter $\alpha$ increased but the parameter $\beta$ decreased with temperature for the present films.
\end{abstract}

\section{LIST OF SYMBOLS}

$\mathbf{R}_{0}, \mathbf{R}_{1}, \mathbf{R}_{\mathbf{2}}$ resistance of the films at various temperatures

$R_{b} \quad$ barrier resistance with resonance tunneling

$\mathrm{R}_{\mathrm{p}} \quad$ barrier resistance with phonon assisted hopping

$\gamma$ temperature coefficient of resistivity (TCR) without hopping

$\gamma_{\mathrm{m}} \quad$ temperature coefficient of resistivity with hopping

$\gamma_{0} \quad$ a mathematical expression as defined in the text

T temperature

$t \quad$ thickness of the films

$\alpha, \alpha^{\prime} \quad$ tunneling parameters (defined in the text)

$\beta \quad$ hopping parameter (defined in the text)

a barrier height parameter

$\mathrm{b}$ temperature coefficient of resistance of $\mathrm{Ru}$

E activation energy

k Boltzmann factor

B Mott's hopping coefficient

B $\quad$ a mathematical expression as defined in the text

\section{INTRODUCTION}

In an earlier paper ${ }^{1}$ we have investigated the possibility of tunneling and hopping mechanism in $\mathrm{RuO}_{2}$ thick film resistors. Our conclusion in that paper was that while both the mechanisms are possible in a thick film resistor for electronic conduction, hopping becomes more important with low concentration ${ }^{\dagger}$ of $\mathrm{RuO}_{2}$ particles. In this paper we will report a detailed experimental study of $\mathrm{RuO}_{2}$ thick film resistors with a view to understanding the behavior of various tunneling and hopping parameters and their relationships. In this context we will also examine the various theories for the conduction

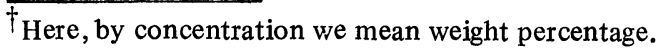


mechanism in $\mathrm{RuO}_{2}$ thick film resistors.

Thick films are fabricated ${ }^{2}$ by means of a screen printing process using a paste containing a mixture of a conductive material, a glass, a binder and a thinner. A definite pattern of interest is first made and printed on a ceramic substrate. This process is repeated with the resistor pattern using the resistor paste. The paste is usually printed on the substrate and fired to form a glaze. The resistors are finally trimmed to proper values for the resistances.

We define the temperature coefficient of resistivity (TCR) by

$$
\gamma=\frac{\left(\mathrm{R}_{2}-\mathrm{R}_{1}\right) \times 10^{6}}{\left(\mathrm{~T}_{2}-\mathrm{T}_{1}\right) \times \mathrm{R}} \mathrm{ppm} / \mathrm{deg}
$$

where $R_{1}$ is the resistance at $T_{1}, R_{2}$ is the resistance measured at $T_{2}$, and $R$ is the average resistance. However, for the temperatur dependence study, we will use

$$
\gamma=\frac{1}{\mathrm{R}}\left(\frac{\partial \mathrm{R}}{\partial \mathrm{T}}\right)(\mathrm{deg})^{-1}
$$

In the above expression, TCR is found by measuring resistance $\mathrm{R}_{0}$ at $0^{\circ} \mathrm{C}$ and resistance $\mathrm{R}$ at temperature T (TCR is defined as the change in resistance per $R$ per degree from $25^{\circ} \mathrm{C}$ to $125^{\circ} \mathrm{C}$ for Department of Defense work). The ideal resistor should have a TCR equal to zero. We will first measure the TCR of $\mathrm{RuO}_{2}$ films with various particle sizes and concentrations of the conductor particles. We will then use these results to compute some important parameters so as to understand the theoretical models proposed earlier ${ }^{1}$ for thick film resistors. We believe it will be possible to see how barrier height, activation energy and hopping parameter influence the TCR. This study will help in the development of a resistor ink with smaller TCR and greater stability. ${ }^{2}$

\section{EXPERIMENTAL MEASUREMENTS}

\subsection{Sample Preparation}

The paste or ink used in this investigation consisted of a conductive material $\left(\mathrm{RuO}_{2}\right)$, a binding material which is a fine glass powder (lead borosilicate), and organic binder (ethyl cellulose) and a volatile solvent (pine oil). The organic binder held $\mathrm{RuO}_{2}$ and glass particles in suspension before firing and provided a proper fluid characteristic for screen printing. Samples with three different particle sizes were obtained from Electro Materials Corporation of America (EMCA), who also mixed them in proper proportions with other ingredients.

The actual resistor consisted of two conductor pads with the film printed between them. The pattern was made in two parts: one for the pad and the other for the film as shown in Figure 1(a). The original pattern was drawn to a scale of five to one making the initial pattern five times larger than the desired resistors. The conductor and resistor patterns were cut separately since they were printed and fired at two different stages. Finally the aspect ratio (length/width) was maintained unity.

The substrate was produced by grinding $\mathrm{Al}_{2} \mathrm{O}_{3}$ to a 2 to 3 micron $(\mu)$ grain size, mixing with magnesium oxide $(\mathrm{MgO})$ and an organic material. This paste-like substance was smoothed, cut to the desired size and fired at $2200^{\circ} \mathrm{C}$. The finished substrate was $96 \% \mathrm{Al}_{2} \mathrm{O}_{3}$ and $4 \% \mathrm{MgO}$. The substrates, printed with the conductor pattern, were dried in air for about fifteen minutes at $150^{\circ} \mathrm{C}$ temperature. Finally, the substrates were placed in a nichrome belt furnace for about twenty-eight minutes to heat at a temperature of $850^{\circ} \mathrm{C}$ for eleven minutes. 


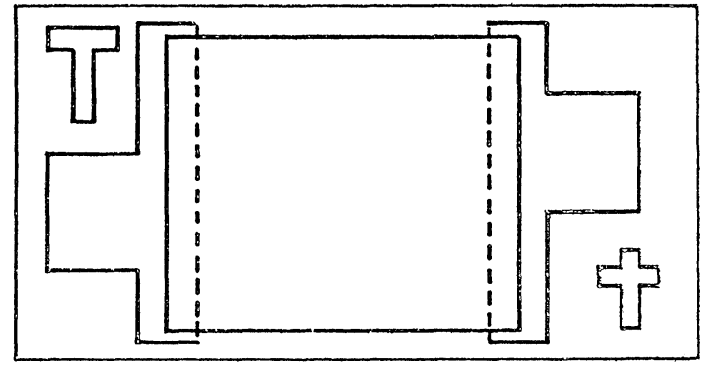

(a)

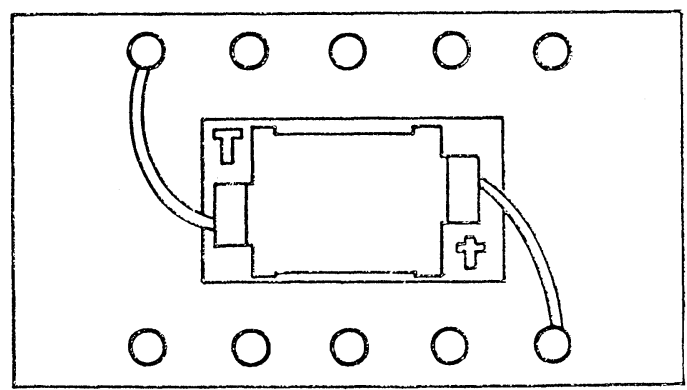

(b)

FIGURE 1 The pattern of a thick film resistor used in this investigation. (a) resistor without contacts; (b) resistor with contacts.

An identical procedure for printing and firing was used for the resistor ink. However, after each resistor was printed, the screen was washed with alcohol and water and then dried with compressed air. The final form of the resistor is shown in Figure 1(b).

\subsection{Measurement of the Temperature Coefficient of Resistivity}

The thickness of the film were traced using a Sloan Dektak MDC-9000 system. The resistances of the films were measured simultaneously using a parallel connection as shown in Figure 2. A standard oven operating in the temperature range of $25 \sim 300^{\circ} \mathrm{C}$ was found suitable for this work. The connecting wires showed no significant change of resistance as temperature changed, and were negligibly small $(0.3 \sim 1.7 \mathrm{ohms}) \mathrm{com}$ pared to the resistances of the films. The resistances were recorded with a five-digit Keithley 174 multimeter. This instrument used a current of $1 \mathrm{~mA}$ for $3 \mathrm{k} \Omega$ and $1 \mu \mathrm{A}$ for $3 \mathrm{M} \Omega$ films. These currents were too small to introduce any additional thermal effect. The temperature was increased gradually in steps of about $15^{\circ} \mathrm{C}$ and was allowed to stabilize for about ten minutes upon reaching the desired temperature.

\subsection{X-Ray Diffraction Measurements of the Thick Films}

The x-ray diffraction patterns of the thick films were recorded on a vertical Philips diffractometer using the flat sample focusing condition. ${ }^{3}$ The Ni-filtered $\mathrm{CuK} \alpha_{1}$ radiation was 
TABLE I

IDENTIFICATION OF SAMPLES

Please note that these were commercial samples which were obtained from EMCA with these specifications. Therefore, the composition and size could not be changed more uniformly.

\begin{tabular}{lcl}
\hline Sample & $\begin{array}{l}\text { Paste } \\
\%\end{array}$ & $\begin{array}{l}\text { Composition } \\
\text { size }\end{array}$ \\
\hline A & 0 & $0.3 \mu$ \\
B & $2 \%$ & 0.3 \\
C & $2 \%$ & 3.1 \\
D & $12 \%$ & 3.1 \\
E & $16 \%$ & 2.2 \\
F & $16 \%$ & 3.1 \\
\hline
\end{tabular}

used. The x-ray beam was collimated through $1^{\circ}$ divergence slit and passed through $0.006^{\circ}$ receiving slit. Each diffraction peak was scanned at $1.0^{\circ}$ per minute scanning speed and recorded at 60 inches per hour paper chart speed. Intensity scale, baseline and time constant were held constant for all samples, since a comparison of peak height, or intensity, and the broadening of the peaks would be made later. Because of the importance of peak tails, care was taken to collect the background level over a sufficiently large angular spread on either side of the peak maximum. All available peaks were recorded. A blank substrate was also run in order to sort out the peaks due to alumina substrate alone.

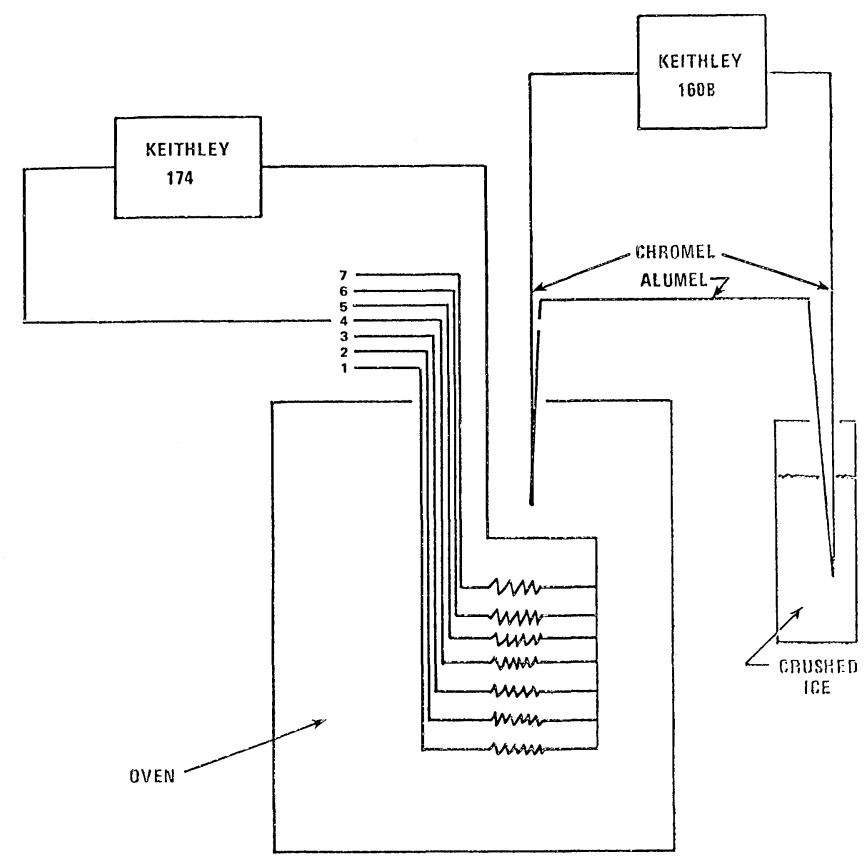

FIGURE 2 Experimental setup for the measurement of temperature coefficient of resistance 


\section{RESULTS OF THE EXPERIMENTAL MEASUREMENTS}

Various samples used in this investigation are identified as shown in Table I. The results of the measurements are illustrated in Figures 3-4. The x-ray data are tabulated in Table II.

We used Eq. (1.2) to calculate our TCR reflecting $\mathrm{T}_{1}=30^{\circ} \mathrm{C}$ and $\mathrm{T}_{2}=250^{\circ} \mathrm{C}$. The plots in Figure 3 show two types of effects: (i) change of resistance with temperature, and (ii) change of resistance with thickness when concentration and particle size are kept constant. Similarly, Figure 4 illustrates: (i) change of resistance with concentration when thickness and particle size are kept constant, and (ii) change of resistance with particle size when thickness and concentration are kept constant.

\subsection{Negative and Positive TCR}

We see from the slopes of plots in Figure 3(a) that the TCR is negative for $2 \%$ concentration films. These plots are designated as a 1 and a2. Instead of the usual rise, these plots show a decrease. If these results were to follow the tunneling model as proposed by Pike and Seager, ${ }^{5}$ a resistance minimum should occur at some temperature $\mathrm{T}_{\mathrm{m}}$. Here we do not find such an effect for $2 \%$ film with 2.2 and $3.1 \mu$ particles. The plots of measured TCR are shown in Figure 5. These values are rather large and may not be suitable for

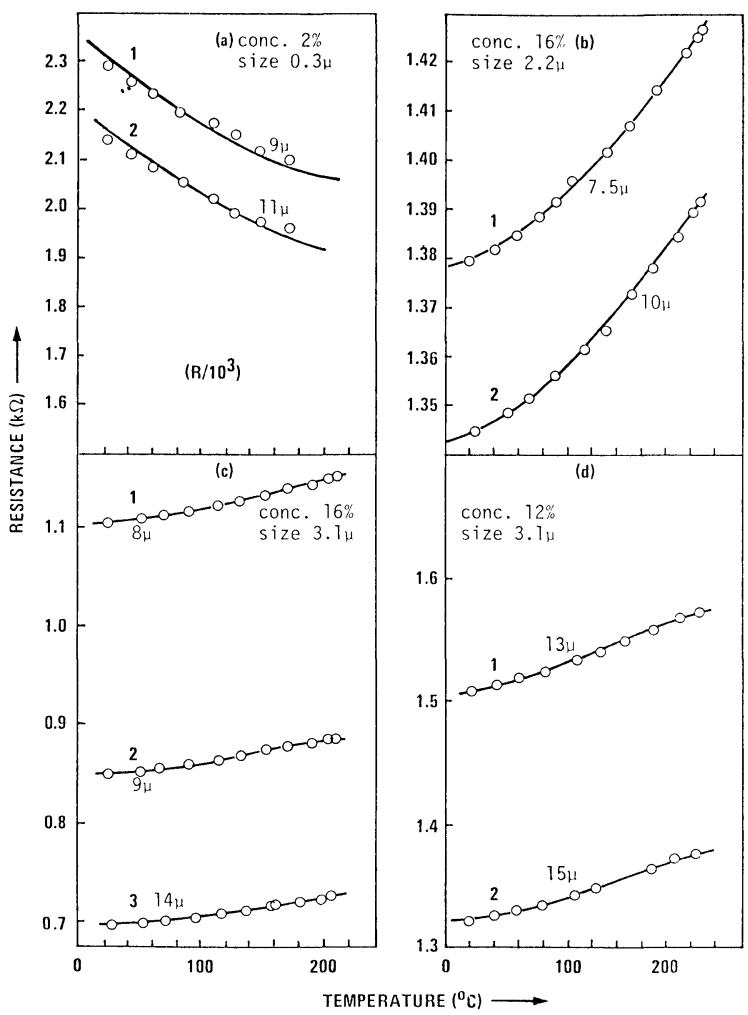

FIGURE 3 Measured temperature dependence of the thick film resistances for various concentrations and sizes of the particles. (a) $2 \%$ and $0.3 \mu$; (b) $16 \%$ and $2.2 \mu$; (c) $16 \%$ and $3.1 \mu$; (d) $12 \%$ and $3.1 \mu$. The effect of thickness is also demonstrated in each of these plots. The results obtained are summarized in Table III. Note that all resistances are plotted in $\mathrm{k} \Omega$ except in (a) which are in $\mathrm{M} \Omega$ 


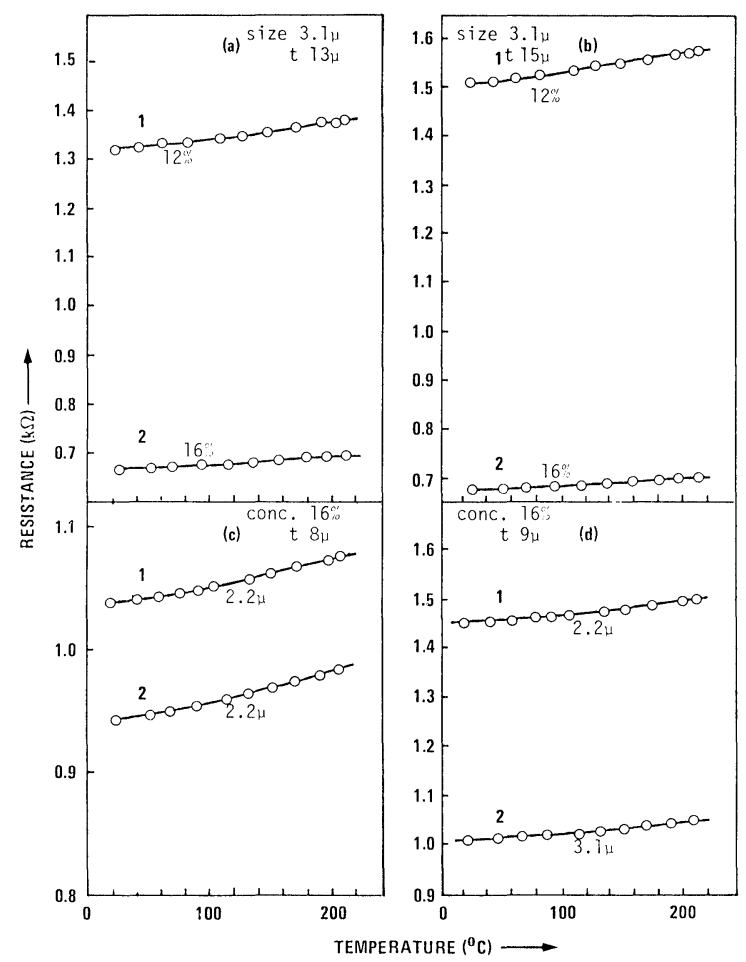

FIGURE 4 Measured temperature dependence of the thick film resistances for various thicknesses of the resistors, sizes and concentration of the particles. (a) $13 \mu$ and $3.1 \mu$; (b) $15 \mu$ and $3.1 \mu$; (c) $8 \mu$ and $16 \%$; (d) $9 \mu$ and $16 \%$. The results obtained are summarized in Table III.

practical use in the microcircuits. ${ }^{6}$ However, these numbers suggest that the effective resistances of these films are predominantly due to tunneling as opposed to metallic condition as observed in pure metallic films.

Figure 3(b), 3(c), and 3(d) show a dependence of TCR on film thickness when particle size and concentration are kept constant. In Figures 3(b) and 3(c) the highest values resistors are the thinnest which is what one would expect, since the resistance should be inversely proportional to thickness. The TCR of these films are positive implying that $T_{m}$ is below $25^{\circ} \mathrm{C}$. In the present investigation, the $2 \%$ films have the highest resistance, the $12 \%$ have a fairly high resistance and the $16 \%$ have a value somewhat less than that of the $12 \%$. This dependence on concentration has been verified by others. ${ }^{7-9}$

Figures 4(a) through 4(d) show the temperature dependence of resistance as functions of particle size and concentration. It is seen that, at these fairly high concentrations $(12 \%$ and $16 \%)$, smaller particle size films have higher resistance. ${ }^{10}$

\subsection{Structural Analysis by Thickness and X-Ray Measurement}

In Figures 6(a) and 6(b) are shown the thickness traces obtained with SLOAN Dektak Model 9000 . The thickness measurement indicates a significant amount of surface irregularities. It is found that resistors with smaller concentration had much smoother surfaces than the ones with higher concentration. The profile is very smooth although the thickness does vary a great deal. Additionally, the surface irregularities appear to be propor- 
TABLE II

X-ray data

\begin{tabular}{lllll}
\hline Sample & $2 \theta^{\circ}$ & $\mathrm{d}(\AA)$ & $\mathrm{h}$ (arb. unit) & $\beta_{0}$ (arb. unit) \\
\hline A & & & $\begin{array}{l}\text { no peak } \\
\text { no peak }\end{array}$ \\
B & & & $\begin{array}{l}\text { no peak } \\
\text { C }\end{array}$ & \\
D & 28.28 & 3.154 & 2.2 & 0.78 \\
& 54.57 & 1.681 & 1.0 & 0.70 \\
E & 28.15 & 3.168 & 2.5 & 1.21 \\
& 54.57 & 1.681 & 1.2 & 0.60 \\
F & 28.00 & 3.145 & 2.0 & 1.45 \\
& 35.30 & 2.541 & 1.7 & 0.89 \\
& 54.57 & 1.681 & 1.1 & 1.05 \\
\hline
\end{tabular}

$\mathrm{d}$ : interplanar spacing $\mathrm{h}$ : peak maximum, $\beta_{0}:$ half width at peak maximum

tional to the concentration in the film. These traces point out an inherent problem with thick film resistors.

As stated previously the diffraction peaks due to the alumina substrate and the lead borosilicate glass were identified by analysis of the $\mathrm{x}$-ray spectra. No peaks due to $\mathrm{RuO}_{2}$ were found in the $2 \%$ film. The $12 \%$ and $16 \%$ resistors do show, however, some small peaks not attributable to the substrate or the lead borosilicate glass. The peak intensity and peak numbers increased with increase of concentration. The observed half widths of the films are inversely proportional to the particle size if we assume that there is no particle strain.

\section{DISCUSSIONS AND CONCLUSIONS}

\subsection{Resonance Tunneling and Parameter $\alpha$}

According to the Pike-Seager theory we expect to see a resistance minimum (or conductance maximum) at $\mathrm{T}_{\mathrm{m}}$. In the present experiment this could perhaps occur above $250^{\circ} \mathrm{C}$. This minimum depends on several factors, most critically on the barrier resistance with positive curvature. A simple tunneling, which is also called 'resonance tunneling', can give such a minimum. Introducing $\gamma$ for TCR, we write as in our previous paper ${ }^{1}$

$$
\gamma=-\alpha^{\prime}\left[\frac{\mathrm{a}^{2} \mathrm{~T}}{3}\left(1+\frac{\mathrm{E}}{4 \mathrm{kT}}\right)+\frac{\mathrm{E}}{2 \mathrm{kT}^{2}}\right]+\frac{\mathrm{b}}{(1+\mathrm{bT})}-\frac{\alpha^{\prime} \mathrm{b}}{(1+\mathrm{bT})}\left(1-\frac{\mathrm{a}^{2} \mathrm{~T}^{2}}{6}\right)\left(1+\frac{\mathrm{E}}{2 \mathrm{kT}}\right)
$$

which gives

$$
\alpha^{\prime}=\left[\frac{\mathrm{b}}{(1+\mathrm{bT})}-\gamma\right]\left[\frac{\mathrm{a}^{2} \mathrm{~T}}{3}\left(1+\frac{\mathrm{E}}{4 \mathrm{kT}}\right)+\frac{\mathrm{E}}{2 \mathrm{kT}^{2}}+\frac{\mathrm{b}}{(1+\mathrm{bT})}\left(1-\frac{\mathrm{a}^{2} \mathrm{~T}^{2}}{6}\right)\left(1+\frac{\mathrm{E}}{2 \mathrm{kT}}\right)\right]^{-1}
$$

whereas, from the exact definition of $\alpha^{\prime}$ we can easily get 
TABLE III

TCR results

\begin{tabular}{lcllll}
\hline & \multicolumn{2}{c}{$\begin{array}{c}\text { From Figure } 3 \\
\text { at } 112^{\circ} \mathrm{C}\end{array}$} & & \multicolumn{2}{c}{$\begin{array}{c}\text { From Figure 4 } \\
\text { at } 112^{\circ} \mathrm{C}\end{array}$} \\
\hline Plots & Thickness & TCR & Plots & Conc. or Size & TCR \\
\hline Symbol & $(\mu)$ & $\left(\mathrm{ppm} /{ }^{\circ} \mathrm{C}\right)$ & Symbol & $(\%)$ & $\left(\mathrm{ppm} /{ }^{\circ} \mathrm{C}\right)$ \\
a1 & 9 & -663 & a1 & 12 & 194 \\
a2 & 11 & -629 & a2 & 16 & 148 \\
b1 & 7.5 & 215 & b1 & 12 & 222 \\
b2 & 10 & 149 & b2 & 16 & 190 \\
& & & & $(\mu)$ & \\
c1 & 8 & 179 & c1 & 2.2 & 162 \\
c2 & 9 & 204 & c2 & 3.1 & 189 \\
c3 & 14 & 163 & & & \\
d1 & 15 & 222 & d1 & 2.2 & 136 \\
d2 & 13 & 194 & d2 & 3.1 & 177 \\
\hline
\end{tabular}

$$
\alpha=\mathrm{R}_{\mathrm{b}} /\left(\mathrm{R}_{\mathrm{b}}+\mathrm{R}_{\mathrm{m}}\right)=\alpha^{\prime}\left[\left(1-\frac{\mathrm{a}^{2} \mathrm{~T}^{2}}{6}\right)\left(1+\frac{\mathrm{E}}{2 \mathrm{kT}}\right)\right]
$$

and that

$$
\alpha^{\prime}=\mathrm{R}_{\mathrm{bo}} /\left(\mathrm{R}_{\mathrm{b}}+\mathrm{R}_{\mathrm{m}}\right)
$$

We can now calculate $\alpha$ for all the films using the data listed in Table III. These values of $\alpha$ are found in the range $2.28 \sim 2.30$. We find that these calculated $\alpha$ 's, specifically for the low concentration films, do not compare with the value $0.7 \sim 0.75$ as suggested by

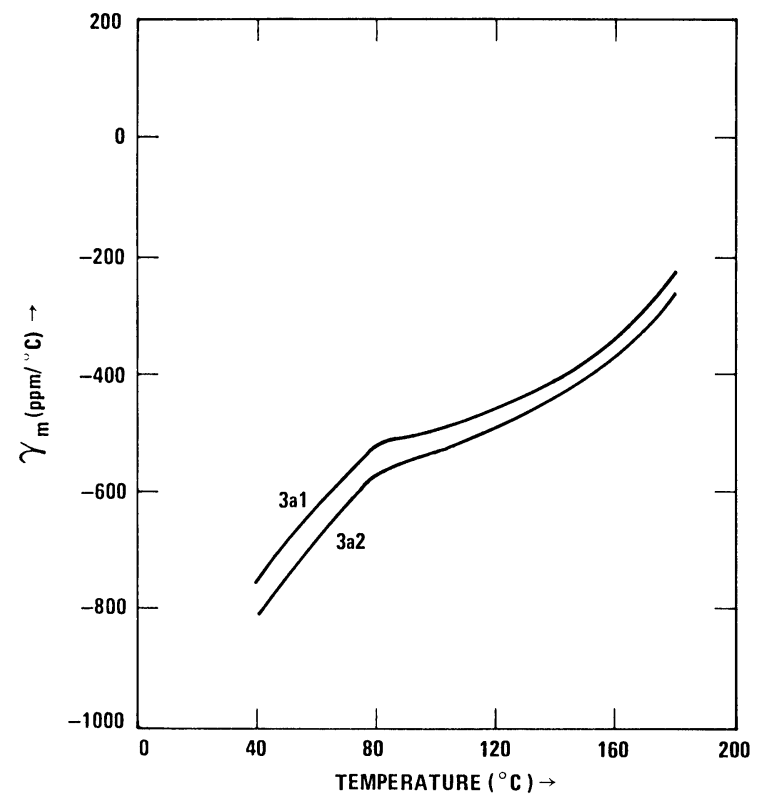

FIGURE 5 The plots of TCR against temperature for two of the films which have negative coefficients 


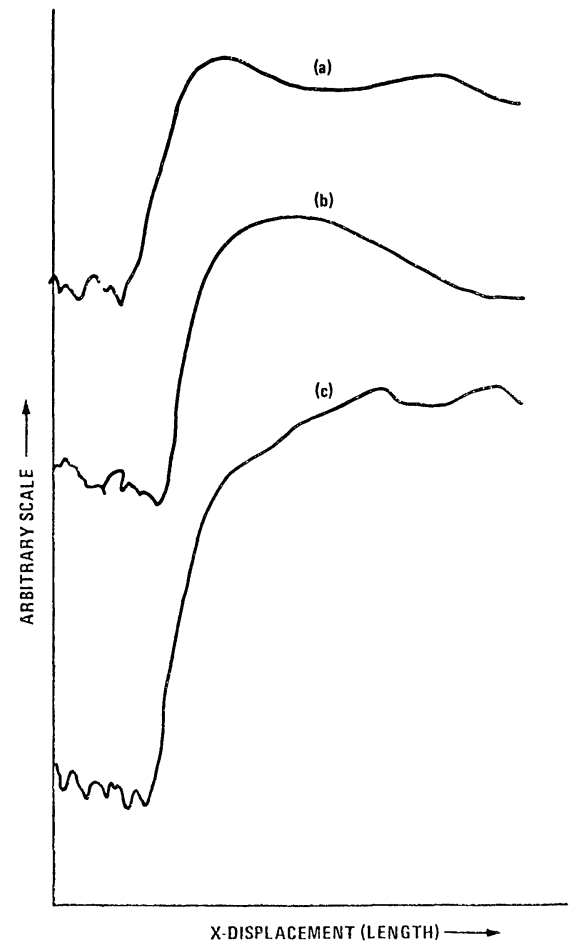

FIGURE 6 The thickness profile of the thick film resistors traced along length (a) for $2 \% \mathrm{RuO}_{2}$ with $0.3 \mu$ size; (b) for $2 \% \mathrm{RuO}_{2}$ with $3.1 \mu$ size; (c) for $12 \% \mathrm{RuO}_{2}$ with $3.1 \mu$ size.

Pike and Seager ${ }^{5}$ for $\mathrm{RuO}_{2}$ films. At this point we would like to recall other possible mechanisms not considered earlier. ${ }^{12-14}$

As has been reported earlier ${ }^{1}$ there are two possibilities for an electron to tunnel through. For narrow barriers, the result is a simple tunneling, ${ }^{15}$ where an electron with less kinetic energy may cross the barrier quantum mechanically without going through any intermediate hopping step. This is in fact what happens in the resonance tunneling and has been discussed in the Pike-Seager ${ }^{11}$ theory. It should be mentioned here that this theory allows (i) the effects of the presence of impurities (resonant centers) in the barrier, and (ii) the correction factor due to the finite size of the metal oxide particles. However, for wide barriers, there is another form of tunneling, the phonon assisted hopping, ${ }^{16,17}$ which involves a number of intermediate hopping steps before the electron can pass through these barriers. We will now address ourselves to this possibility.

\subsection{Phonon Assisted Hopping and Parameter $\beta$}

In the present paper we will follow the work of our previous paper ${ }^{1}$ and denote the barrier resistance as $R_{b}$ and hopping resistance as $R_{p}$; then the effective barrier resistance as $R_{B}$ may be written either in the parallel mode or in the series mode. Thus for parallel mode the TCR equation will be 


$$
\begin{aligned}
\gamma_{\mathrm{m}} & =\frac{\gamma(1+\beta)}{(1-\alpha+\beta)}-\frac{\alpha^{\prime}(1+2 \beta)}{(1+\beta)^{2}}\left[\left(1-\frac{\mathrm{a}^{2} \mathrm{~T}^{2}}{6}\right) \frac{\mathrm{E}}{2 \mathrm{kT}^{2}}+\left(1+\frac{\mathrm{E}}{2 \mathrm{kT}}\right) \frac{\mathrm{a}^{2} \mathrm{~T}}{3}\right] \\
& -\frac{\mathrm{BT}^{-5 / 4}}{4} \frac{\alpha \beta}{(1+\beta)(1-\alpha+\beta)}
\end{aligned}
$$

where

$$
\beta=\mathrm{R}_{\mathrm{p}} / \mathrm{R}_{\mathrm{b}}
$$

we can now get an expression for $\alpha$ from this equation,

$$
\alpha=\left[(1+\beta)\left(\gamma-\gamma_{\mathrm{m}}\right)-\gamma_{0}\right]\left[-\gamma_{\mathrm{m}}+\frac{\mathrm{BT}^{-5 / 4}}{4} \frac{\beta}{(1+\beta)}\right]^{-1}
$$

where

$$
\begin{aligned}
\gamma_{0}= & \alpha\left[\left(1-\frac{\mathrm{a}^{2} \mathrm{~T}^{2}}{6}\right)\left(1+\frac{\mathrm{E}}{2 \mathrm{kT}}\right)\right]^{-1}\left[\left(1-\frac{\mathrm{a}^{2} \mathrm{~T}^{2}}{6}\right) \frac{\mathrm{E}}{2 \mathrm{kT}^{2}}+\left(1+\frac{\mathrm{E}}{2 \mathrm{kT}}\right) \frac{\mathrm{a}^{2} \mathrm{~T}}{3}\right] \\
& \frac{(1+2 \beta)(1-\alpha+\beta)}{(1+\beta)^{2}}
\end{aligned}
$$

We see clearly from Eq. (4.5) that there is no simple solution for $\alpha_{.}$However, in the approximation $\alpha<<(1+\beta)$, which may be valid in some cases, the above equation reduces to

$$
\gamma_{\mathrm{m}}=\gamma\left[1+\frac{\alpha}{1+\beta}\right]-\left[\left(1-\frac{\mathrm{a}^{2} \mathrm{~T}^{2}}{6}\right) \frac{\mathrm{E}}{2 \mathrm{kT}^{2}}+\left(1+\frac{\mathrm{E}}{2 \mathrm{kT}}\right) \frac{\mathrm{a}^{2} \mathrm{~T}}{3}\right] \frac{(1+2 \beta)}{(1+\beta)^{2}}
$$
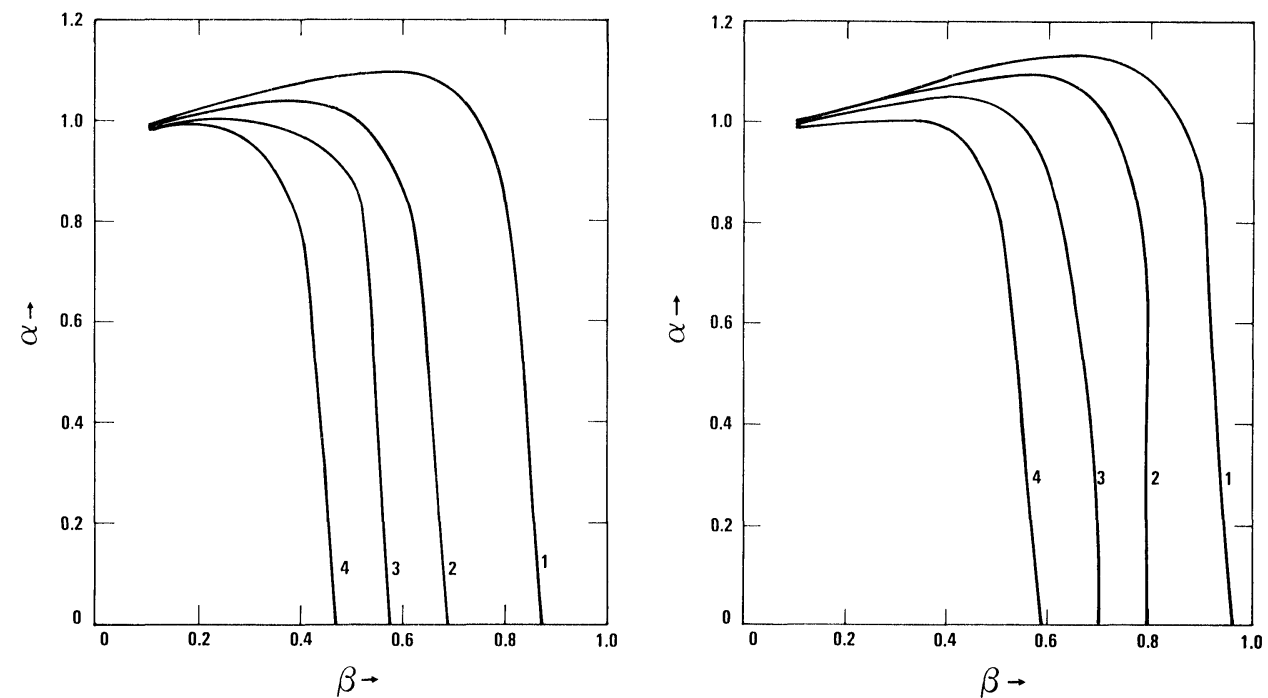

FIGURE 7 The plots of $a$ against $\beta$ for films in $3 \mathrm{a} 1$. Curve $1: 60^{\circ} \mathrm{C}$; curve $2: 70^{\circ} \mathrm{C}$, curve $3: 80^{\circ} \mathrm{C}$; curve 4: $100^{\circ} \mathrm{C}$ (a) The parallel mode, as shown in (a), was obtained with Eq. (4.7) (b) The series mode, as shown in (b), was obtained with Eq. (4.12) 


$$
\alpha^{\prime}-\left(\frac{\mathrm{BT}^{-5 / 4}}{4}\right) \frac{\alpha \beta}{(1+\beta)^{2}}
$$

which gives

$$
\begin{gathered}
\alpha=\left(\gamma_{\mathrm{m}}-\gamma\right)\left\{\frac{\gamma}{(1+\beta)}-\left[\frac{\left(1-\frac{\mathrm{a}^{2} \mathrm{~T}^{2}}{6}\right) \frac{\mathrm{E}}{2 \mathrm{kT}}+\left(1+\frac{\mathrm{E}}{2 \mathrm{kT}}\right) \frac{\mathrm{a}^{2} \mathrm{~T}}{3}}{\left(1-\frac{\mathrm{a}^{2} \mathrm{~T}^{2}}{6}\right)\left(1+\frac{\mathrm{E}}{2 \mathrm{kT}}\right)}\right]\right. \\
\left.\frac{1+2 \beta}{(1+\beta)^{2}}-\left(\frac{\mathrm{BT}-5 / 4}{4}\right) \frac{\beta}{(1+\beta)^{2}}\right\}-1
\end{gathered}
$$

It is, however, possible to return to the Pike-Seager theory as illustrated in Eqs. (4.2) and (4.3) by letting $R_{p}$ become infinitely large, in which case $R_{B}$ will approach $R_{b}$.

On the other hand if, however, $R_{b}$ and $R_{p}$ were considered in series, one could easily show that

$$
\gamma_{\mathrm{m}}=\frac{\gamma(1+\beta)}{(1-\alpha+\beta)}-\frac{\mathrm{B}^{\prime} \mathrm{T}^{-5 / 4}}{4} \frac{\alpha \beta(1+\beta)}{(1-\alpha+\beta)}
$$

and

$$
\alpha=(1+\beta)\left(\gamma-\gamma_{\mathrm{m}}\right)\left[-\gamma_{\mathrm{m}}+\frac{\mathrm{B}^{\prime} \mathrm{T}^{-5 / 4}}{4} \beta(1+\beta)\right]^{-1}
$$

which again, in the approximation $\alpha<<(1+\beta)$, will reduce to

$$
\gamma_{\mathrm{m}}=\gamma\left[1+\frac{\alpha}{1+\beta}\right]-\frac{\mathrm{B}^{\prime} \mathrm{T}^{-5 / 4}}{4} \alpha \beta
$$
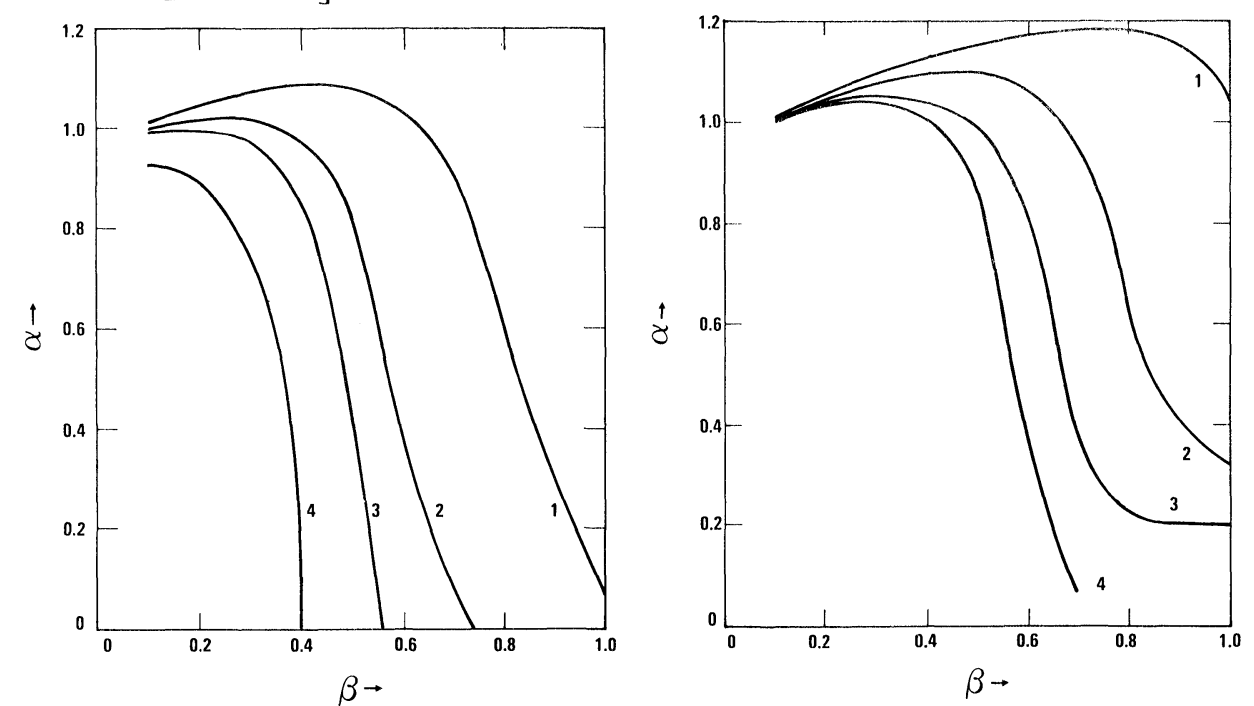

FIGURE 8 The plots of $a$ against $\beta$ for films in $3 \mathrm{a} 2$. Curve $1: 70^{\circ} \mathrm{C}$; curve $2: 80^{\circ} \mathrm{C}$; curve $3: 90^{\circ} \mathrm{C}$; and curve $4: 100^{\circ} \mathrm{C}$. (a) The parallel mode, as shown in (a), was obtained with Eq. (4.7) (b) The series mode, as shown in (b), was obtained with Eq. (4.12) 
and

$$
\alpha=\left(\gamma-\gamma_{\mathrm{m}}\right)\left[\frac{\mathrm{B}^{\prime} \mathrm{T}^{-5 / 4}}{4} \beta-\frac{\gamma}{(1+\beta)}\right]^{-1}
$$

where

$$
B^{\prime}=B \frac{(1-\alpha+\beta)}{(1+\alpha \beta)(1+\beta)}
$$

We shall now examine the implication of these derivations.

\subsection{Concluding Remarks}

We have made numerical calculations of $\alpha$ using $\mathrm{a}=5 \times 10^{-4} /{ }^{\circ} \mathrm{K}$, and $\mathrm{b}=5 \times 10^{-4} /{ }^{\circ} \mathrm{K}$ and $\mathrm{E}$ as given previously. ${ }^{1}$ We utilized an iteration method to obtain $\alpha$. For Figures 3a 1 and $3 \mathrm{a} 2$, since they have negative TCR, we included both the resonance tunneling and phonon assisted hopping. The plots of $\alpha$ against $\beta$ are shown in Figures 7 and 8 at various temperatures. However, the values of $\alpha$ and $\beta$ determined from these graphs are given in Table IV. As these plots indicate, both $\alpha$ and $\beta$ are significant for films with negative TCR. When we attempted to apply the same equations for films with positive TCR some unphysical values for $\alpha(5 \sim 30)$ were obtained. On the other hand, when we calculated $\alpha$ for these films, which have positive TCR without the phonon assisted hopping, we

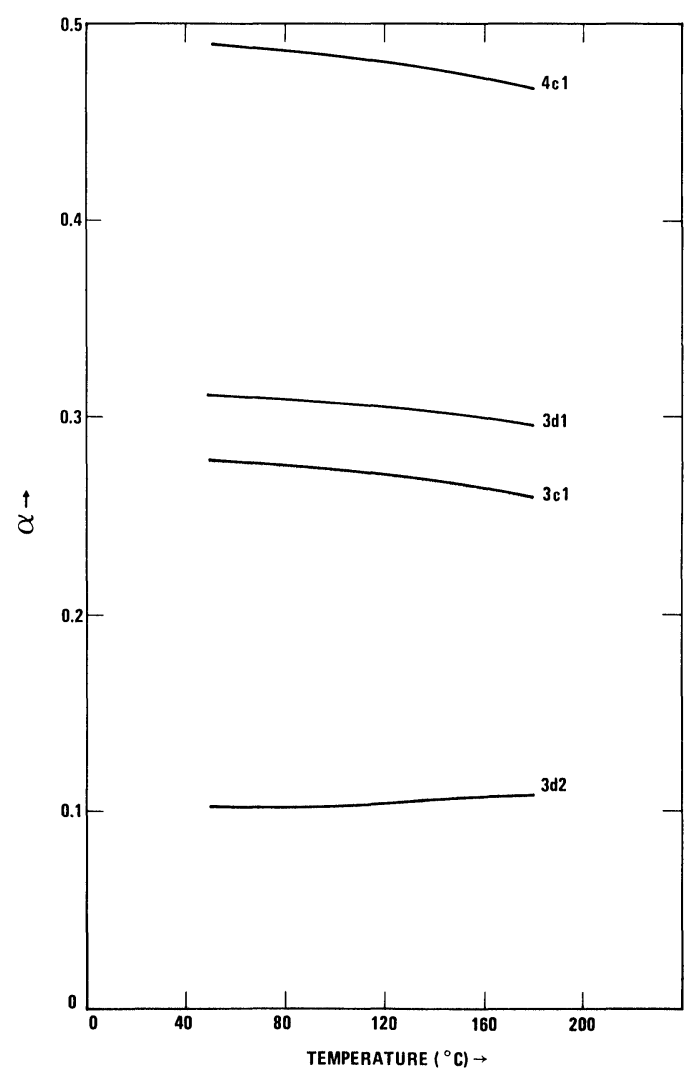

FIGURE 9 The plots of $\alpha$ against temperature for some of the films with positive TCR. These films do not have any $\beta$ 
TABLE IV

Calculated values from Figs $3 \mathrm{a} 1$ and $3 \mathrm{a} 2$ for parallel and series connections of $R_{b}$ and $R_{p}$

\begin{tabular}{ccccccccc}
\hline & \multicolumn{4}{c}{ Film 3a1 } & \multicolumn{3}{c}{ Film 3a2 } \\
\hline \multicolumn{3}{c}{ Parallel } & \multicolumn{2}{c}{ Series } & \multicolumn{3}{c}{ Parallel } & \multicolumn{3}{c}{ Series } \\
Temp & $\mathrm{q}$ & $\beta$ & $\alpha$ & $\beta$ & $\alpha$ & $\beta$ & $\alpha$ & $\beta$ \\
\hline $60^{\circ} \mathrm{C}$ & .80 & .80 & .80 & .91 & .43 & .82 & - & - \\
70 & .85 & .60 & .85 & .76 & .55 & .56 & .54 & .82 \\
80 & .94 & .44 & .96 & .57 & .83 & .38 & .22 & .82 \\
100 & .94 & .33 & .99 & .39 & .84 & .25 & .02 & .82 \\
& & & & & & & &
\end{tabular}

obtained reasonable results. These results are demonstrated in Figure 9. We also show the behavior of $\alpha$ with $\gamma$ at mean temperature of $112^{\circ} \mathrm{C}$ in Figure 10.

From this study it is seen that films with large $\alpha$ have small $\beta$ and vice versa, $\alpha$ tends to increase but $\beta$ tends to decrease with temperature. This study further points out that the parallel mode is more likely than the series mode. The series mode results of film $3 a 2$ in Table IV are not to be accepted for this reason. It should be mentioned here that the temperature dependence of $\alpha$ and $\beta$ are not the same.

As pointed out before, phonon assisted hopping is a form of tunneling. However, resonance tunneling does not directly depend on temperature. Its dependence comes mainly from the Fermi-Dirac distribution function that describes the occupancy of the electron states, whereas the hopping does depend on the temperature in a direct way.

We may now summarize the results of this investigation. Films with larger particle size had higher resistance than those with smaller particle size. For low concentration films resistance decreased as temperature increased indicating a $\mathrm{T}_{\mathrm{m}}$ somewhere above $250^{\circ} \mathrm{C}$. These were explained by extending the tunneling model to phonon assisted hopping. The results of the present study seem to confirm the Pike and Seager ${ }^{5}$ model in the high concentration films but not necessarily in the low concentration films. The tunneling parameter $\alpha$ and hopping parameter $\beta$ are both affected by temperature. The nature of the temperature dependence, however, is not the same. It is further noted that the particle size and concentration are the two most critical parameters which influence the behavior of the resistor. The distribution of particle size depends very much on the preparation technique and firing process, which in turn, fixes the resistance minimum at $T_{m}$.

\section{REFERENCES}

1. N.C. Halder, Electrocompo. Sci. Technol., 11, 21 (1983).

2. D.M. Consadine, Van Nostrand's Scientific Encyclopedia, Van Nostrand Reinholt Co., 1976.

3. N.C. Halder, Z. Naturforsch, 34a, 176 (1979); N.C. Halder and M. Pita, J. Vac. Sci. Technol. 17, $621(1980)$

4. C.A. Schaffer and J.E. Sergent, Proc. ISHM Hybrid Microelectron Sym. p. 60, Oct. 1977, Baltimore, Md.; C.A. Schaffer, "Thick film resistors with $\mathrm{RuO}_{2}$ ", Master's Thesis, University of South Florida (unpublished), 1978.

5. G.E. Pike and C.H. Seager, J. Appl. Phys. 48, 5152 (1978); C.H. Seager and G.E. Pike, "Electrical properties of dupon birox and cermalloy" Thick Film Resistors I (SAND75-0019) and II (SAND76-0558), Sandia Laboratories, Feb. 1975 and May 1977.

6. R.W. Vest, "Conduction mechanism in thick film microcircuits", Final Technical Report, ARPA Order Number 1642, Dec. 1975.

7. D.A. Cash, M.P. Ansell and R.M. Hill, "Investigation of conduction mechanisms in thick films," Ministry of Defense, United Kingdom, 1973. 


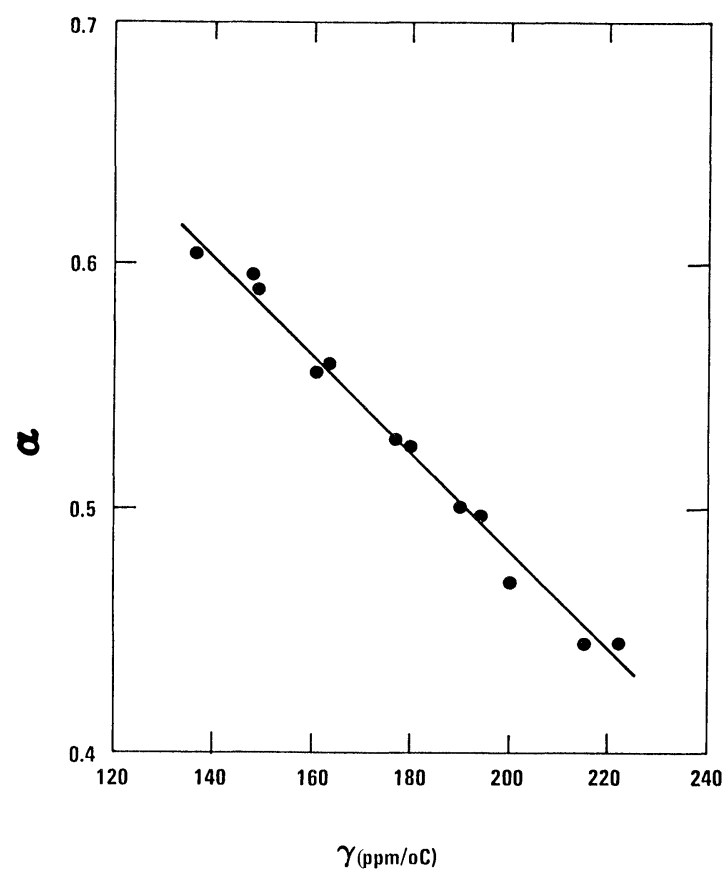

FIGURE 10 The plots of $\alpha$ against $\gamma$ for all the films with positive TCR at one temperature (mean temperature) $112^{\circ} \mathrm{C}$.

8. J.G. Rhee, "The noise properties of thick film resistors", Ph.D. Thesis, University of South Florida, (Unpublished), 1979.

9. T.M. Chen and J.G. Rhee, Sol. State Technol. 20, 49 (1977); J.G. Rhee and T.M. Chen, Sol. State Technol. 21, 59 (1978).

10. T. Kubota, "Variations of electrical characteristics with the basic compositions of palladium-silver thick film resistors", Proc. ISHM Hybrid Microelectron. Sym., 1970, p. 8.6.1; "Effects of particle size control in the metal powder systems on the characteristics of palladium silver thick film resistors", Proc. Electronic Components Conf., 1970, p. 514.

11. C.H. Seager and G.E.Pike,Phys. Rev. B 10, 1435 (1974); G.E. Pike, Phys. Rev. B 6, 1572 (1972).

12. W.D. Kingery, J. Appl. Phys. 30, 301 (1959).

13. W.D. Kingery and M. Berg, J. Appl. Phys. 21, 301 (1950).

14. R. Stratton, J. Phys. Chem. Sol. 23, 1177 (1962).

15. C.B. Duke, "Tunneling phenomena in solids", edited by E. Berstein and S. Lundquist, Plenum Press, 1969.

16. N.F. Mott, J. Non-Cryst. Solids 1, 1 (1968);Phil. Mag. 19, 835 (1969).

17. N.F. Mott and E.A. Davis, Electronic Process in Non-Crystalline Solids, Clarendon Press, Oxford, 1979. 

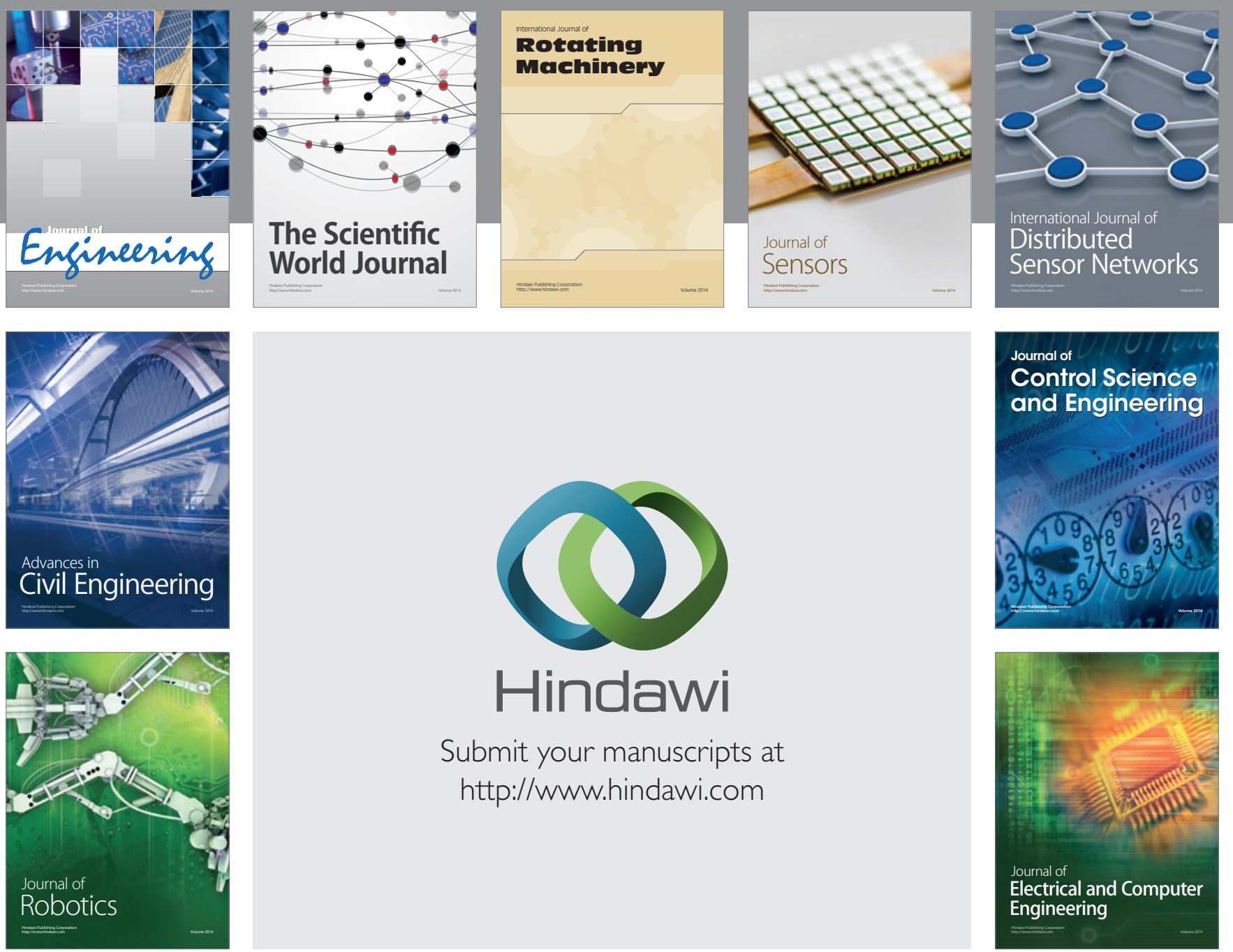

Submit your manuscripts at

http://www.hindawi.com
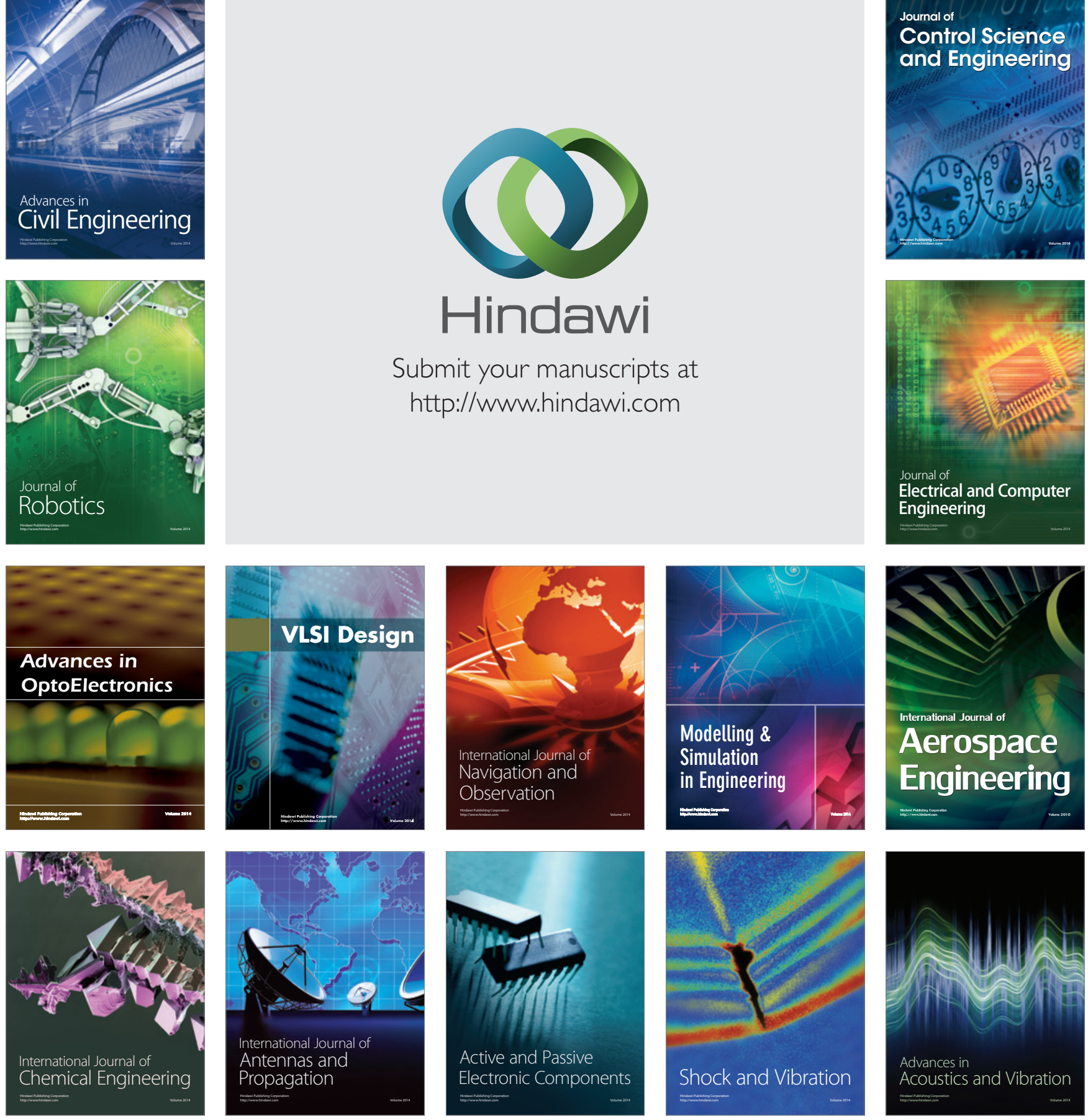